\title{
A CONSTRUÇÃO DO CAMPO
}

COMUNICAÇÃO/EDUCAÇÃO

A construção do campo comunicação/educação como novo espaço teórico capaz de fundamentar práticas de formação de sujeitos conscientes é tarefa

complexa, que exige o reconhecimento dos meios de comunicação como um outro lugar do saber, atuando juntamente com a escola.

Para avançar nessa elaboração, é preciso buscar conhecer o lugar onde os sentidos se formam e se desviam, emergem e submergem: a sociedade, com seus comportamentos culturais, levando-se em conta, principalmente, a pluralidade de sujeitos que habita cada um de nós.

$\mathrm{Na}$ complexidade desse encontro - comunicação/educação - os sentidos se ressignificam e a capacidade de pensar criticamente a realidade, de conseguir selecionar informação (disponível em número cada vez maior graças à tecnologia, Internet, por exemplo) e de inter-relacionar conhecimentos, torna-se indispensável.

Afinal, como viver numa sociedade onde a circulação de bens simbólicos está imbricada na sua própria porosidade, parecendo levar à perda da vitalidade? Qual o campo cultural no qual circulamos e no qual formamos nossa identidade? Conhecer seus mecanismos é um dos caminhos para que o jogo sujeito/objeto (este, constituído pelos bens simbólicos, que são as formas simbólicas mercantilizadas) seja operado num processo de interação efetiva e não de mera subordinação.

\section{DAS FORMAS SIMBÓLICAS AOS BENS SIMBÓLICOS}

Em nossa sociedade, mesmo o consumo de bens materiais vem cercado de significados simbólicos (passear num Uno Mille é bem diferente de passear num Marea, embora ambos sejam carros da mesma empresa e se destinem às mesmas finalidades). Com isso estamos querendo ressaltar que, mesmo quando a materialidade é uma das faces de um bem, a outra é a sua face simbólica, ou seja, agregam-se ao material os valores de uma determinada cultura. Em outras situações, o uso e circulação de bens simbólicos incidem predominantemente sobre sua face cultural, sua face propriamente simbólica. É o que ocorre com o uso de um certo tipo de cabelo (o penteado afro, por exemplo) ou de roupas (como as batas), bens simbólicos utilizados por um grupo étnico para marcar uma identidade, incidindo, portanto, diretamente na esfera cultural, como lembra Solange M. Couceiro de Lima ${ }^{1}$.

\section{A AUTORA}

Maria Aparecida Baccega

Professora Livre-Docente do Departamento de Comunicações e Artes da ECA-USP. Diretora Editorial da Revista Comunicaçāo \& Educação. 
Como vemos, as formas simbólicas passam por processos de avaliação dos quais resultam valorização e conflito. Desse modo, confere-se determinado "valor" às formas simbólicas. Para Thompson ${ }^{2}$, podemos falar de dois tipos de valores: valor propriamente simbólico, "o valor que as formas simbólicas possuem em virtude da maneira como elas são apreciadas pelas pessoas que as produzem e as recebem, em virtude das maneiras como elas são apreciadas ou denunciadas, queridas ou desprezadas por esses indivíduos" e valor econômico, que pode ser entendido como "o valor que as formas simbólicas adquirem em virtude de serem trocadas no mercado". Sujeitas à valorização econômica, as formas simbólicas tornam-se mercadorias, os bens simbólicos, que circulam no mercado, podendo ser comprados, vendidos ou trocados.

Os meios de comunicação são os grandes responsáveis pela circulação das formas simbólicas mercantilizadas, ou seja, pela circulação de bens simbólicos. Para tratarmos da questão do consumo de bens simbólicos, quer circulem agregados ou não a uma face material, temos, portanto, que tratar da mídia e nos aproximarmos da complexidade que cerca a produção e circulação do conjunto de bens culturais que ela produz.

Logo, é necessário, também, falar-se de cultura. E colocar a questão dos meios de comunicação nesse campo. Ocorre que, para se fazer tal discussão, os pólos costumam se aguçar e se armar: de um lado, os apocalípticos, os que condenam a priori os meios de comunicação, considerando-os os demônios da contemporaneidade, destruidores da família, da ética, dos valores humanos, enfim; de outro, os integrados, os que se rendem, também a priori, endeusando-os e atribuindo a eles o sagrado papel de sustentáculos do progresso; de um lado, os tradicionalistas, que têm uma visão elitista de cultura; de outro, os que aceitam incluir os meios de comunicação no campo da cultura, com a ressalva, porém, de que se trata de uma diminuição, que eles se constituem em instrumentos de degradação da cultura. Enquanto isso, os meios de comunicação foram crescendo e se articulando, garantindo uma presença cada vez mais relevante na sociedade contemporânea. Mesmo assim, mais que um objeto de estudo, os meios têm sido vistos como algo a ser exorcizado, a ser banido das fronteiras dos homens, das fronteiras do que se elegeu considerar cultura.

\section{COMUNICAÇÃO/EDUCAÇÃO: TRANSDISCIPLINARIDADE}

É preciso enfrentar a discussão, perceber o campo, construí-lo como objeto científico, conhecê-lo, pois são os meios que, contemporaneamente, atribuem significado à realidade, conformando nossas identidades. Sua presença envolve a todos, percorrendo todos os níveis: do internacional ao nacional, ao local; do individual ao particular, ao genérico, enlaçando-os, num movimento permanente de ir e

2. THOMPSON, J. B. Ideologia e cultura moderna. Teoria social crítica na era dos meios de comunicação de massa. Petrópolis: Vozes, 1995, p. 23. 
vir. Eles apresentam profundas implicações no funcionamento da sociedade contemporânea, participando ativamente do processo educativo.

Nessa condição, os meios têm sido, há algum tempo, um dos objetos das Ciências Sociais: Sociologia, Antropologia, Psicologia, Pedagogia etc., estudados a partir do olhar de cada uma delas. A concepção de campo da comunicação e, especificamente, do campo da comunicação/educação é recente e está em fase de construção.

O campo da comunicação/educação é multi e transdisciplinar: Economia, Política, Estética, História, Linguagens, entre outros saberes, o compõem. Cada um deles dialoga com os outros, elaborando, desse modo, um aparato conceitual que coloca os meios no centro das investigações e procura dar conta da complexidade do campo. São as pesquisas que resultam desse diálogo entre os saberes que nos permitem apontar os meios de comunicação como os maiores produtores de significados compartilhados que jamais se viu na sociedade humana, reconhecendo-se, desse modo, sua incidência sobre a realidade social e cultural.

\section{COMUNICAÇÃO/EDUCAÇÃO E CAMPO CULTURAL: MEDIAÇÕES}

A realidade em que estamos imersos, e que contribuímos para produzir, modificar e reproduzir, é sempre uma realidade mediatizada, que passa por vários filtros, por vários intermediários. Retomando Paulo Freire, diríamos que o "estar no mundo e com o mundo" inclui, obrigatoriamente, hoje, no conceito de mundo a mediação, a leitura do mundo que nos é oferecida pelos meios de comunicação. Trata-se, enfim, de saber ler e interpretar o mundo que, metonimicamente, eles nos passam como sendo a totalidade e saber reconfigurar essa totalidade.

Ao tratar do papel da mídia na atualidade, José Arbex ${ }^{3}$ diz o seguinte: "A mídia, em particular a televisão, cumpre um papel essencial na manutenção da ordem neoliberal. Cabe à mídia recriar diariamente o mundo à sua própria imagem $\mathrm{e}$ semelhança, ordenando e contando a História de acordo com os seus interesses. Daí a função estratégica das grandes redes mundiais de televisão e das agências internacionais ${ }^{4}$ de notícia. Elas pautam o mundo, determinam o que pode e o que deve ser visto, uniformizam a informação que será distribuída. Ao noticiar a crise financeira, por exemplo, adotam o discurso fabricado pelas matrizes do capitalismo (Fundo Monetário Internacional, Banco Mundial etc.). Esse discurso, por sua vez, será reproduzido pelos jornais e televisões nacionais. Cria-se, assim, um certo consenso internacional sobre as causas e os remédios da crise"s.

3. ARBEX, J. A vitória da amnésia. Caros Amigos. São Paulo: Casa Amarela, n. 19, out. 1998. p. 8-9.

4. Ver MOREIRA, S. V. O mundo pelas agências de notícias. Comunicação \& Educação. São Paulo: CCAECA-USP/Moderna, n. 5, jan./abr. 1996. p. 23-26.

5. Sobre o tema, consultar, entre outros: BACCEGA, M. A. Do mundo editado à construção do mundo. Comunicação \& Educação. São Paulo: CCA-ECA-USP/Moderna, n. 1, set./dez. 1994. p. 7-14. Conhecimento, informação e tecnologia. Comunicação \& Educação. São Paulo: CCA-ECA-USP/Moderna, n. 11, jan./abr. 1998. p. 7-16. 
Pesquisas em todo o mundo indicam que as pessoas ficam expostas em média de três a quatro horas diárias à televisão. Outras revelam que a exposição aos meios, incluindo a mídia impressa, cobre a terceira parte do tempo dos seres humanos nas sociedades industrializadas, perdendo apenas para "dormir" e "trabalhar" 6 . Apesar disso, continua faltando uma institucionalização adequada dos estudos de mídia, capaz de colocar-se entre o "leitor" dos meios e os produtos dos meios, de maneira a se obter uma leitura mais científica, mais crítica e menos senso comum. (A leitura dos produtos veiculados pelos meios apenas pelo senso comum tem grande importância para a manutenção do status quo, uma vez que esse tipo de leitura não necessita de comprovações e opera no sentido da recepção acrítica.) Esse, um dos resultados das lutas travadas entre os apocalípticos e os integrados, entre os elitistas e os que consideram pejorativamente os meios: sua expulsão do âmbito da pesquisa, negando-lhes prestígio (base para os financiamentos), dificultando e até impossibilitando estudos e sistematizações que tivessem a mídia como objeto principal.

Enquanto isso, os meios de comunicação, e em particular o rádio e a televisão, foram se desenvolvendo (e muito se deve ao avanço da tecnologia), enraizaram-se e já se tornaram centrais na prática cultural, sendo utilizados como o recurso mais importante em termos de consumo cultural.

Para dar conta dessa nova realidade, é preciso ampliar o conceito de cultura. Bechelloni considera que o conceito de campo cultural poderá ajudar. Para ele, "o campo cultural é constituído de um conjunto de relações sociais ativadas pelos atores, instituições e empresas especializadas na produção e circulação de bens culturais e simbólicos; o mercado dos bens simbólicos é o lugar de reconhecimento do campo cultural'?.

O campo cultural, assim conceituado, comporta tanto aqueles que produzem nos limites das artes tradicionais (sentido restrito) quanto, em sentido ampliado, "os sujeitos que contribuem para a produção, distribuição e circulação de bens simbólicos constituídos pelas formas modernas da comunicação, compreendendo a indústria cultural e as artes pós-eletrônicas: da fotografia ao cinema, do rádio à televisão, do design à moda, do periódico ao livro. Os agentes do campo cultural ampliado produzem e consomem bens simbólicos ativados pelas mídias pré e póseletrônicas (tradicionais, novas, novíssimas)"8.

O campo cultural no sentido ampliado tem como sujeito principal os meios de comunicação, juntamente com a escola e outras agências de formação. Aqui se percebe o campo comunicação/educação.

\section{IMPORTÂNCIA DO RÁDIO E DA TELEVISÃO}

Tomando como referentes o tempo e o dinheiro, Bechelloni sustenta que podemos falar de três tipos de mídia: as velhas mídias - livro, periódico, filme - que

\footnotetext{
6. BECHELLONI, G. Televisione come cultura. I media italiani tra identitá e mercato (Televisão como cultura. A mídia italiana entre a identidade e o mercado). Napoli: Liguori, 1995. p. 47.

7. BECHELLONI, G. Televisione come cultura. I media... op. cit. p. 49. grifo nosso.

8. Idem. Ibdem. p. 49.
} 
custavam aos fruidores tanto tempo quanto dinheiro; as novas mídias (o rádio e a televisão) que custam aos fruidores apenas tempo, pois o acesso a elas é gratuito; e as novíssimas mídias (o videocassete, a TV a cabo, o pay per view, o computador) que trazem também para o fruidor um custo em tempo e em dinheiro.

Como se vê, o tempo, que não é passível de ampliação, está presente em todos os tipos. Dentro de seus limites reside a nossa possibilidade de reorganização, de nova edição do mundo pautado e editado pela mídia. Por isso, a competência para a escolha e a condição de inter-relação entre os fatos que só o conhecimento amplo e sólido de Linguagens, História, Antropologia, Sociologia, Filosofia etc. possibilita tornam-se o desafio central na formação de cidadãos. E aqui o papel da escola e do professor emergem, ressignificados. Também aqui se percebe a importância da construção do campo comunicação/educação.

A classificação apresentada possibilita também que se perceba a importância do rádio e da televisão, com destaque para a televisão, a qual, em virtude da linguagem que utiliza, construída na conjunção do verbal e do não-verbal, torna "real", como se fosse completo, o fragmento editado que o telespectador vê/ouve. $\mathrm{O}$ acesso gratuito a esses meios possibilita-lhes penetrar em todas as classes sociais, o que os tornou "o recurso mais importante", fonte de referência para o consumo cultural.

Segundo Eugênio Bucci ${ }^{9}$, em 1994 o Brasil possuía 34 milhões de domicílios com televisores, constituindo o sexto maior parque de aparelhos televisores do mundo, perdendo apenas para Estados Unidos, Japão, Rússia, Alemanha e China. Se tomarmos a proporção número de aparelhos/ habitantes, o Brasil está na $56^{\text {a }}$ posição, com 207 aparelhos para cada 1.000 habitantes. Em 1982 eram 15,8 milhões de lares com televisão, o que significa que em pouco mais de dez anos esse número dobrou. São constatações como essas que levam o autor a afirmar, logo no início do Prefácio: "O espaço público no Brasil começa e termina nos limites postos pela televisão. (....) O que é invisível para as objetivas da TV não faz parte do espaço público brasileiro. O que não é iluminado pelo jorro multicolorido dos monitores ainda não foi integrado a ele" 10 .

(Não consigo deixar de registrar uma história altamente elucidativa e confirmatória da afirmação de Bucci. Quando da morte de Wladimir Herzog, em 1975, a lingüista Ada Natal Rodrigues ministrava um curso no Nordeste. Recebeu a notícia por telefone e, extremamente chocada, foi comentá-la com os alunos. Todos duvidaram, achando que deveria ser apenas um boato, pois, afinal, não tinha saído no Jornal Nacional. Isso corrobora, também, o nível de veridicção - para a população em geral, naquele momento - que a já famosa afirmação do General Médici, no seu período de exercício do governo ditatorial, contém. Segundo ele, era muito bom assistir ao Jornal Nacional, pois através dele se podia verificar o quanto o Brasil era uma ilha de paz num mundo conturbado. Isso, num momento em que as torturas, mortes e desaparecimentos dos que se opunham ao regime estavam no auge e a censura era a tônica.)

9. BUCCI, E. Brasil em tempo de TV. São Paulo: Boitempo, 1997. p. 14.

10. BUCCI, E. Brasil em tempo... op. cit. p. 11. 
A TV é, hoje, o mais importante dos meios de comunicação pela linguagem que utiliza, pois "convida permanentemente o telespectador a identificar a 'realidade' com aquilo que ele vê, e o telespectador se sente confortável por ter acesso tão direto, tão imediato ao mundo 'real'" 11 . É desse modo que ela une o Brasil: construindo o espaço público. E essa construção nem sempre se dá (ou na maior parte das vezes não se dá) a partir de critérios que levem em consideração a cidadania. No mais das vezes, atende a interesses forjados pelo ideário dominante e divulgados em escala mundial. E assim vão-se formando as gerações.

\section{CULTURA DA MÍDIA}

A cultura da mídia se manifesta em um conjunto articulado e diversificado de produtos (pólo do enunciador/emissor) que entram em relação com o conjunto articulado e diversificado de vivências do enunciatário/receptor, cujo universo de valores, posto em movimento, ativa os significados dos produtos. Na verdade, a cultura da mídia não está no enunciador/emissor, não está no enunciatário/receptor: está no território que se cria nesse encontro, gerando significados particulares, que se contêm interseção com cada um dos pólos, não se limitam a nenhum deles. Caso contrário, a mídia seria apenas "veículo" de significados e não "construtora" de significados. Sua complexidade reside exatamente no fato de, construindo significados no território que inclui cada um dos pólos - enunciador/emissor e enunciatário/receptor - ela exigir permanentemente a dialética entre o "já visto" e o "por ver", ou seja, a "novidade" que responde pelas e alimenta as mudanças contínuas de identidade versus a "estabilidade" que cada grupo social busca em sua dinâmica. O único limite é o horizonte da formação social na qual estão e que inclui tanto o já manifesto quanto o ainda virtualmente contido como possibilidades a serem realizadas.

Por essas e incontáveis outras razões, podemos perceber como é fundamental a construção do campo comunicação/educação. Ele inclui, mas não se resume a: educação para os meios, leitura crítica dos meios, uso da tecnologia em sala de aula, formação do professor para o trato com os meios etc. etc. Ele se rege, sobretudo, pela construção da cidadania, pela inserção neste mundo editado, com o qual todos convivemos, no qual todos vivemos e que queremos modificar.

Esse é o objetivo que Comunicação \& Educação persegue: a construção do campo comunicação/educação, num movimento que percorre permanentemente $o$ todo e as partes, em intercâmbio permanente. Ou seja: do território digital a ArteEducação, de meio ambiente a educação a distância, entre muitos outros tópicos, sem esquecer os vários suportes, as várias linguagens - televisão, rádio, teatro, cinema, jornal etc. Tudo percorrido com olhos da congregação dessas agências de formação: a escola e os meios, sempre no sentido da construção da cidadania. 


\section{ARTIGOS NACIONAIS}

Internet no ensino, de José Manuel Morán, é o artigo que abre a seção. Mostra as possibilidades do uso da Internet em sala de aula, contando passo a passo as próprias experiências do autor, enquanto professor. Aponta vantagens e alerta para os cuidados necessários: os alunos se impressionam "primeiro com as páginas mais bonitas, que exibem mais imagens, animações, sons"; "a tendência dos alunos de quantificar, mais que analisar"; o fato de haver "informações demais e conhecimentos de menos". Enfatiza o papel do professor: "Mais que a tecnologia, a comunicação autêntica do professor" é que garante o êxito do trabalho. E reafirma a necessidade de novos paradigmas educacionais: caso contrário, o uso da Internet será apenas "um verniz, um paliativo ou uma jogada de marketing".

Termos como ciberespaço e território digital, Internet e intranet, entre muitos outros, passaram a circular quase sem que nos déssemos conta. Na verdade, eles têm como referencial uma realidade que também foi se impondo quase sem que percebêssemos. E agora ela já está instalada. Fábio Duarte, em Democracia no território digital, torna claros esses e outros conceitos, mostra como essa nova realidade se relaciona com democracia e como, sendo global, atua no local. Alerta, porém, para um dado fundamental: "é claro que essas ações funcionam apenas quando as regiões envolvidas têm, ao menos, conexão telefônica”. Segundo a Folha de S. Paulo, de 16 de setembro de 1998, o Censo Educacional do MEC revelou que 47\% das instituições de ensino de $1^{\circ}$ grau no Brasil ainda não possuem linha telefônica. Que fazer?

"As coisas sem as pessoas são letra morta", diz Alfredo Bosi, citado no artigo Transdisciplinaridade: o desafio de inovar, de Maria Inês F. Miranda et al. Neste trabalho, a teorização sobre a transdisciplinaridade vai se construindo junto com a leitura da prática efetivada pelos autores. Afinal, dizem os autores, "a prática multiprofissional deve ser construída de tal forma que cada um seja capaz de ter uma concepção integral do indivíduo". Para tanto, para que as pessoas estejam acima das "coisas", é fundamental que se efetive "uma construção conjunta", com a participação dos vários saberes. Hoje, a capacitação de alunos para as habilitações tradicionais já não cabe. "Trata-se de ter em vista a formação dos estudantes em termos de sua capacitação para a aquisição e o desenvolvimento de novas competências, em função de novos saberes (transdisciplinares) que se produzem e demandam um novo tipo de profissional, preparado para poder lidar com novas tecnologias e linguagens capazes de responder a novos ritmos e processos".

"A democratização do saber deve passar por um ensino que trabalhe a possibilidade de construir conhecimentos novos, indissociáveis das realidades sociais". Nesse cenário se desenvolve o artigo Comunicação, ensino e temática ambiental, de Arlêude Bortolozzi. Segundo a autora, é preciso que ocorra "uma mudança da visão fragmentada da problemática ambiental por parte dos professores, para uma visão na qual ocorra a interligação e a interdependência entre os fenômenos sociais, econômicos, físicos, políticos e culturais". Ou, em outras palavras: o tema deve ser tratado a partir da transdisciplinaridade, com a participação dos vários saberes. Deve ser tratado no campo da comunicação/educação. A autora mostra o re- 
ducionismo que caracteriza a abordagem do tema, quer seja pela TV, quer seja pelas posturas operadas nas escolas. Mostra a postura da Unesco, que inter-relaciona educação ambiental com "economia, sociedade, política e ecologia", a da Constituição Brasileira de 1988 e a do Programa Estadual de Educação Ambiental.

Marisa Tsubouchi da Silva, em Ensino de arte nos Estados Unidos e no Brasil, aponta a ousadia do termo Arte-Educação, mostrando-o como o resultado de um processo que incluiu várias posturas sobre o ensino de arte. Segundo a autora, o desafio do professor de Arte-Educação é "fazer arte no cotidiano da escola, sem perder de vista a relação dialética entre processos sensíveis, emocionais e sociais e o ensino da disciplina e seus processos sensíveis e cognitivos".

Arte-Educação, ética e estética lembra que "formação e informação devem acontecer através de vivências, no mesmo fazer". Assim o autor, Ilo Krugli, mostra que a escola deve abrir as portas da afetividade, que permite o fazer livre. Ele propõe "aulas de experimentação, projetos e conteúdos que resgatem e dêem vida a rituais coletivos nos quais a imaginação, as sensibilidades artísticas, as identidades aconteçam fora das programações competitivas ou dos festejos estereotipados do consumo, dos calendários cívicos e comerciais em que a criatividade e a arte são programadas nas agências publicitárias e nos escritórios gerenciais dos shoppings".

\section{ARTIGOS INTERNACIONAIS}

O artigo de Roberto Aparici - Ensino, multimídia e globalização - aborda, inter-relacionando, questões extremamente importantes para os avanços do campo comunicação/educação: a globalização da economia, a mundialização da cultura, a privatização dos espaços públicos, as novas tecnologias, a difusão, através dos meios de comunicação organizados em redes, de conteúdos que suportam uma visão de mundo uniforme, o papel da escola, entre outras. Segundo o autor, o objetivo da escola "é conseguir que os alunos estejam em contato com as experiências e acontecimentos que ocorrem no mundo e, ao mesmo tempo, fortalecer a identidade cultural, o pertencer a um contexto específico". Para isso, é fundamental que a educação forme os educandos para "a divergência, a reflexão, a autonomia e a crítica". Apresentando os dados sobre o tráfego na rede, Aparici mostra o quanto a tecnologia colabora para que aumentem as distâncias entre países ricos e países pobres, que ele chama de inforricos e infopobres. Termina alertando para, entre outras, a necessidade da elaboração de "novas teorias e paradigmas vinculados ao novo contexto comunicacional e informacional".

Mário Kaplún, em Processos educativos e canais de comunicação, começa por lembrar que "comunicação não é um mero instrumento midiático e tecnológico, e sim, antes de tudo, um componente pedagógico". A partir da reafirmação da importância da escola "como espaço gerador da socialização e possibilitador das interações grupais", indispensáveis à educação, o autor discute a questão dos usos das tecnologias e da educação a distância. Alerta para a necessidade de que os meios na educação "sejam aplicados crítica e criativamente, a serviço de um projeto pedagógico, ultrapassando a mera racionalidade tecnológica". 


\section{ENTREVISTA}

Em Uma dama na cena livre, Eva Wilma, entrevistada por Roseli Fígaro, vai nos contando seu trajeto profissional como bailarina, atriz de cinema, de teatro e de televisão. Do seriado Alô, doçura! até o seriado Mulher, em exibição, ela contextualiza seu relato com a voz da cidadã que habita na atriz. Relembra Esperando Godot, peça que encenava em 1976-1977 e que o Brasil inteiro traduzia por Esperando a democracia. Reflete sobre telenovela, ressalta a importância da dramaturgia e fala de seus projetos.

\section{CRÍtítCA}

Finalmente há algo de novo neste campo: foi retomada a produção cinematográfica brasileira. Tânia Pellegrini, em Novo cinema brasileiro, fala desse processo. Mostra a pluralidade de temas dessa retomada, destacando, porém, a presença dos filmes históricos. Analisa $O$ que é isso, companheiro? e Central do Brasil, mostrando que se diferenciam pela fala: o primeiro fala inglês e o segundo, português.

\section{DEPOIMENTO}

Ricardo Kotscho, um dos mais respeitados jornalistas, pela competência e coerência, dá seu depoimento em Jornalismo: uma opção. Trabalhou em vários jornais e revistas, escreveu livros e hoje dirige o jornalismo da TV Bandeirantes e do Canal 21. Segundo Kotscho, "a pauta da nossa grande imprensa já não nasce nas ruas e nos campos, nas escolas e nas fábricas, entrando nas redações sem pedir licença. Chega como prato feito dos gabinetes oficiais para eternizar os donos do poder e afastar qualquer risco de mudança". Como trabalhar essa realidade faz parte deste depoimento.

\section{EXPERIÊNCIA}

Existem temas que, embora façam parte do cotidiano dos alunos, acabam não sendo tratados por terem a aura do tabu. O aborto é um deles. Márcia Regina Viotto decidiu enfrentá-lo. Ela é professora de Sociologia, numa escola estadual. É isso que Márcia nos conta em Tema do aborto nas aulas de Sociologia.

\section{POESIA}

Brecht é o escolhido. Seu poema, Assim passei o tempo que me deram na terra, é uma manifestação de historicidade, construída com a mágica poética. Vale a pena se emocionar e crescer com ele. 


\section{SERVIÇOS}

Oswaldo Sangiorgi, em Cibernética e educação, além de nos dar uma aula, oferece os serviços do Centro de Cibernética Pedagógica, que coordena. Comunique-se com ele. Você e seus alunos sairão ganhando.

\section{BOLETIM BIBLIOGRÁFICO}

A seção Videografia, como os leitores certamente já perceberam, foi sofrendo modificações. Hoje ela se constitui num roteiro de atividade pronto para ser desenvolvido com os alunos. Essas mudanças se devem à Professora. Maria Ignês Carlos Magno, que continua a responder pela seção. Neste número, o tema é Meio ambiente e ensino fundamental, tratado de maneira transversal, como a realidade exige. (E como vários artigos neste número já apontaram.)

Bibliografia sobre telenovela brasileira, de Anamaria Fadul, e Bibliografia de Comunicação e Educação, de Ismar de Oliveira Soares, que compõem o Boletim Bibliográfico, continuam trazendo referências importantes para os estudos dessas temáticas.

Resumo: 0 artigo trata da construção do campo comunicação/educação, inserindo-o na cultura. Aborda três aspectos desse campo: a circulação dos bens simbólicos, a transdisciplinaridade que o forma, as mediações dos meios de comunicação que, editando o mundo, formulam e divulgam uma única versão da realidade. Aponta a importância do rádio e da televisão. Mostra a cultura da mídia como construtora de significados, os quais se constituem na base da formação das identidades. Recusando visões maniqueitas (ou emissor ou receptor), que levariam à compreensão da mídia apenas como veiculadora de significados, defende uma visão dialógica, inserindo a construção desses significados no território que se estabelece entre ambos os pólos.

Palavras-chave: cultura, televisão, formas simbólicas, mediações, campo comunicação/educação
Abstract: The article deals with building the field of communication/education, inserting it in culture. It touches on three aspects of this field: the circulation of symbolic goods; the transdisciplinary characteristic that forms it; and the mediation of the means of mass communication which, while editing the world, formulate and divulge a single version of reality. It points to the importance radio and television have had. Furthermore, the article presents media culture as one that builds eanings that constitute the base for the formation of identities. Refusing Manichean views (either emitter or receptor), that would lead to the understanding of the media simply as a vehicle for meanings, it defends a dialogical view, inserting the construction of these meanings into the territory that is established between both poles.

Key words: culture, television, symbolic forms, communication/education field 